\title{
Review
}

\section{Exercise and Life-Satisfactory-Fitness: Complementary Strategies in the Prevention and Rehabilitation of IIInesses}

\section{Christiane Jennen and Gerhard Uhlenbruck}

\author{
Institute of Immunobiology, University of Cologne, 50924 Cologne, Germany.
}

\begin{abstract}
Moderate training of an endurance nature, but also other exercise activities, not only has a preventive effect on various illnesses and pre-illness states such as the metabolic syndrome and cancer, but is also effective in treating patients in the rehabilitation phase after illness, e.g. cardiovascular or cancer. Our investigation demonstrates that even low level physical activity has a very good preventive effect too, which is enhanced when it is accompanied by mental activity and psychological well-being. In total, we investigated 13000 people on the basis of socio-economic panel polls with respect to life contentment, health status and leisure-time activities. Life contentment is positively linked to contentment with labor, which seems to be an essential aspect with regard to the increasing number of unemployed people in Europe. The second important factor is health-promoting activities during leisure time. Exercise, especially, has a significant influence on life satisfaction as a feeling of physical fitness feeling is regarded as synonymous with good health. The results underline the psycho-neuroimmunological network, which stabilizes our health and shows that different activities in older adults have a significant effect on the aging process and age-related illnesses. Besides the various activities that are important in this arena, namely muscle and mental mobility ('brawn and brain'), a third component must be taken into consideration: life contentment in the form of a successful retrospective view and a positive outlook, embedded in a psychosocial family environment ('brood') and integrated in a stress-free biotope, where life does make sense. Alternative and complementary strategies should be considered in light of these three aspects when we think about additional anti-inflammatory strategies in preventing diseases or treating them and their relapses.
\end{abstract}

Sport has made a few healthy people ill, but sport has also made a good few of ill people healthy!

(Gerhard Uhlenbruck, Aphorisms)

Keywords: exercise - fitness - grandchildren - health-satisfaction - leisure time activity - lifecontentedness - wellness

\section{Introduction}

One of the most effective complementary strategies during a post-illness rehabilitation program for various illnesses (heart and circulation, metabolic syndrome and also cancer) is

\footnotetext{
For reprints and all correspondence: Christiane Jennen, Institute of Immunobiology, University of Cologne, 50924 Cologne, Germany. Email: christianejennen@gmx.de
}

moderate endurance exercise training, which up-regulates antiinflammatory, health promoting processes in nearly all body tissues. There are a great number of references to this subject in the handbook of Beuth (1) on the importance of complementary methods, where we also have summarized all our results dealing with exercise in post-cancer-care groups.

With respect to this additive and complementary therapeutic approach, it was of great interest to us to investigate the psychosocial, cultural and health aspects of regular exercise in a

The online version of this article has been published under an open access model. Users are entitled to use, reproduce, disseminate, or display the open access version of this article provided that: the original authorship is properly and fully attributed; the Journal and Oxford University Press are attributed as the original place of publication with the correct citation details given; if an article is subsequently reproduced or disseminated not in its entirety but only in part or as a derivative work this must be clearly indicated. 
German population; particularly as this form of fitness treatment also has enormous preventative benefit with regard to various illnesses, including cancer.

It is therefore the aim of this review to focus on the analysis of the influence of exercise and fitness on the level of satisfaction in health and leisure time activities as well as their relationship to cultural activities and family situation in a modern society, especially with respect to illnesses in older adults. It has been found that the influence of exercise on a person's sense of well-being and perceived fitness in various groups of people over age 50 is significant. The frequency of exercise greatly influences the perceived wellness of older adults (2). In addition, other psychological parameters such as relationships with children and grandchildren are also important variables for mental health, which, in return, may stabilize the immune system. Exercise seems to be the most efficient strategy with respect to healthy aging, as has been shown in many papers in recent years.

In this respect it is notable to mention a recent study which comes to the conclusion, that maintaining or adopting a moderate or high degree of physical activity is associated with a lower risk of death across a wide range of ages in both sexes (3). The paper also gives a comprehensive literature survey on this subject. In recent years we have worked on complementary or 'alternative' methods in post-cancer-care patients. We have found that moderate exercise with these patients stimulates natural killer-cell activity, reduces relapses, stabilizes mental fitness, reduces fatigue syndrome and helps them to cope with their illness by raising their self-consciousness. All of our results have been included in recent editions of a standard handbook on complementary treatment in cancer patients $(1,4)$.

In recent years, researchers have also found that psychosocial factors greatly influence the immune system: they are a vital source for the feeling of well-being and life satisfaction throughout the life span (5). Another important factor associated with wellness and life satisfaction in older adults is social participation (6). Participation in social groups has a direct influence on one's happiness. This research in 'activity theory' (7) can be applied to diverse concepts such as group activity, physical activity, hobbies, artistic and cultural activities.
Numerous studies have demonstrated that social support greatly impacts health-related behavior (e.g. 8).

For the purpose of this study, the measurement of life satisfaction involves 'an attempt to understand the processes by which an individual views his/her past as well as feelings about present lifestyle and future expectations' (6). Research dealing with life satisfaction in older adults has been approached from several perspectives.

Developmental theorists have focused on the identification of positive characteristics and 'challenges' to adults with a major focus on the growth processes that go along with aging. The challenges that people face during adulthood have been identified by Erikson (1959) as emotional relationships, performance of tasks and assessment of life. He connects adulthood with the development of a sense of family and an established vocational role. In later adulthood, retirement causes people to detach from people and activities of which they have been a part for many years. 'Acquiring and maintaining life satisfaction has been viewed as the most enduring of life's tasks' (6).

The best method of evaluating life satisfaction is to study the subjective responses individuals give (9). Thus, this socioeconomic study on exercise, fitness and life satisfaction investigates the various relationships between perceived health, life contentment and enjoyment during leisure time of the older adult population in Germany, with special focus on physical activity (Fig. 1).

As Fig. 1 shows, mental distress is mainly induced by lost life expectations and major disappointments, which may lead to depression and resignation, which, in turn, result in inactivity. Exercise, however, seems to be an effective antidote if practiced correctly. Too little exercise, e.g. once a week, has no physical training effect, whereas extreme and overly ambitious exercise in the long run may cause a cortisol and Il-1 plus Il-6-induced stress overloading syndrome caused by a reduced glucose metabolism of brain cells, to which older adults are more susceptible. Regular aerobic endurance training, e.g. three times a week for about 20-30 min, has the best training effect, and thus can positively counteract mental distress.

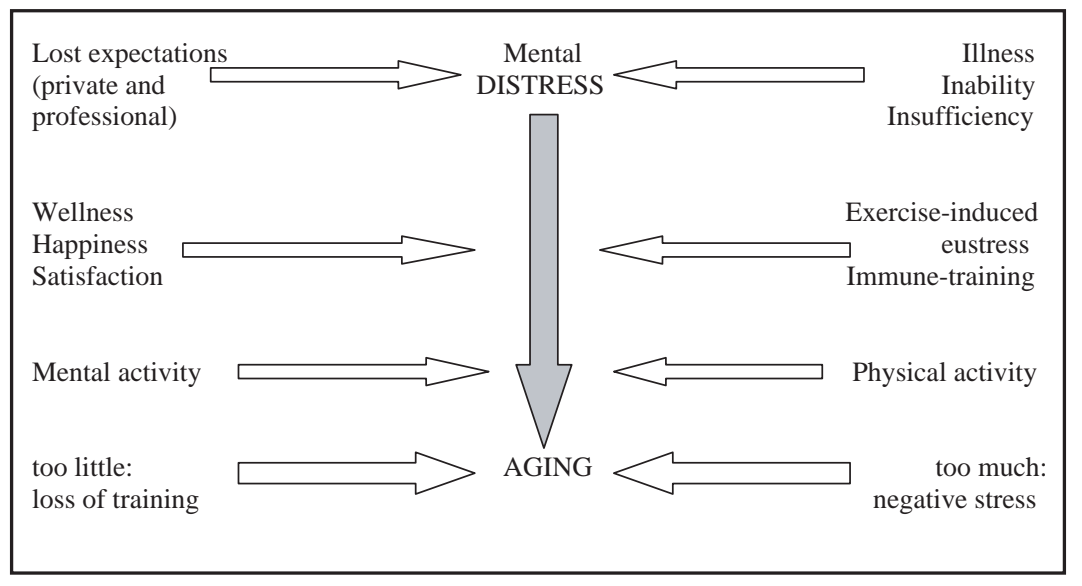

Figure 1. Mental distress, exercise and aging [according to Uhlenbruck $(2,16)]$. 


\section{Subjects and Methods}

The social-economic study (SOEP) delivers reliable facts about persons and households in Germany. The SOEP is a panel which gives representative data about people over 16 years (households and families) based on a questionnaire designed by the Universities of Frankfurt and Mannheim in collaboration with the German Institute for Economic Research in Berlin (DIW). The first interviews were conducted in 1984 in about 6000 households; since then these studies have been continued with a different number of households every year. For our study, interviews from 1990 and 1991 were analyzed. The samples were selected with the 'random-route' (10).

Further information about the statistical methods and analyses, for example the generation of the classifications 'satisfied $\rightarrow$ not satisfied' or 'relationship close $\rightarrow$ not so close' can be found in the thesis of Christiane Mielke (11) and in the SOEP (12); the former also includes the $P$-values for statistical relevance and the significance values. All statistical methods have been checked thoroughly by the Institute for Medical Documentation and Statistics of the University of Cologne.

\section{Results}

The findings of the study are grouped into three areas: (i) the influence of exercise and physical activity on life satisfaction, (ii) cultural and artistic engagement during the aging process and (iii) life satisfaction of people over 50 in their relationship with grandchildren. Some of the results are illustrated with detailed figures.

\section{Exercise and Physical Activity}

In general, $44.7 \%$ perform no exercise at all, whereas $27.4 \%$ of the population do exercise occasionally (seldom, minimum of once a month) and $27.3 \%$ perform regular exercise daily or at least once a week (11).

The percentage of people over 50 who perform daily exercise is between 2.2 and $2.7 \%$. With increasing age, the engagement in exercise activities decreases rapidly (Fig. 2).

Fig. 3 shows the different frequency of exercising between women and men. In every group of sporting people, the percentage of participating men is always higher than that of participating women. The proportion of those taking daily exercise includes $2 / 3$ men $(64.8 \%)$, the proportion of those performing no exercise includes nearly $2 / 3$ women $(57.0 \%)$.

Life satisfaction changes in the different age groups: from the sixth decade on it is about $6.5 \%$ higher than in the previous age groups, which then amounts to $50.7 \%$ (11).

Fig. 4 shows the relationship between the frequency of exercise activity and life satisfaction. Life satisfaction reaches the highest level for those performing exercise and sport activities on a daily basis. Life satisfaction is diminished when people are not as physically active.

When comparing men and women with respect to the frequency of exercise activity versus life satisfaction, we can obtain the following results. The percentage of woman satisfied with their life in the group of the daily exercising $(67.9 \%)$ is $3 \%$ higher than the corresponding figure in the male population $(64.7 \%)$. This difference also applies for the women and men exercising a minimum of once a month $(60.5 \%$ versus

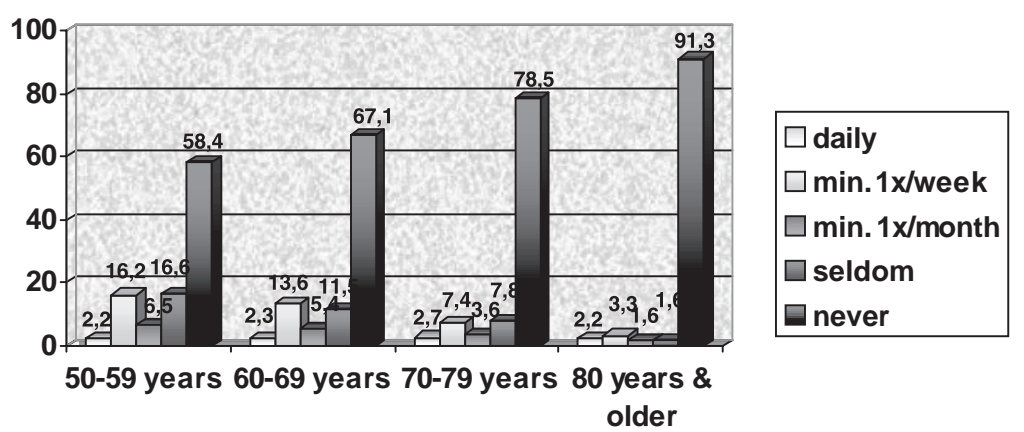

Age $\mathrm{n}=\mathbf{3 2 4 8}$ frequency of sports activity
Figure 2. Age versus frequency of sports activity.

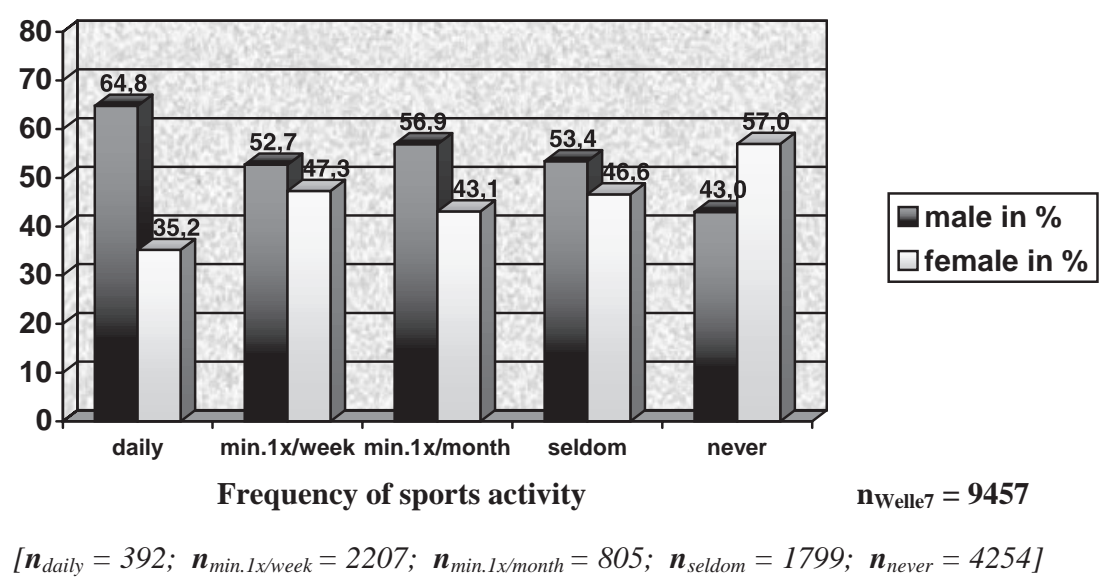

Figure 3. Sex versus frequency of sports activity. 


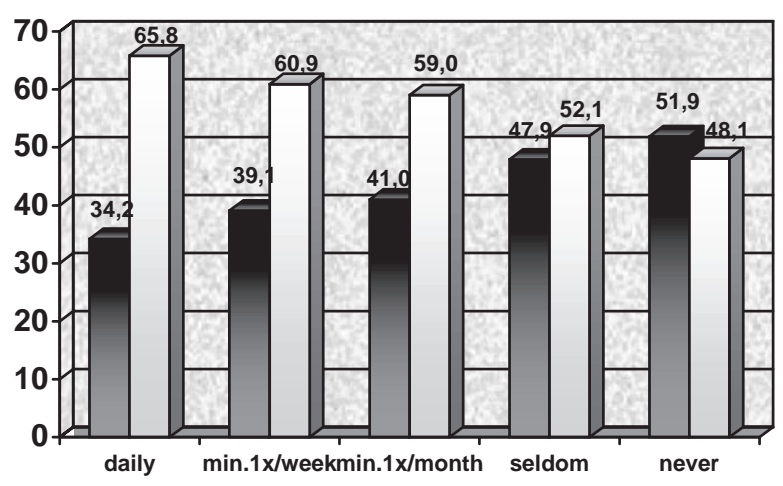

Frequency of sports activity

\section{not satisfied with life in \% $\square$ satisfied with life in \%}

$$
\left[\boldsymbol{n}_{\text {daily }}=389 ; \boldsymbol{n}_{\text {min. } 1 x / \text { week }}=2197 ; \boldsymbol{n}_{\text {min. } 1 x / \text { month }}=803 ; \boldsymbol{n}_{\text {seldom }}=1789 ; \boldsymbol{n}_{\text {never }}=4243\right]
$$

$\mathrm{n}_{\text {Welle7 }}=9421$

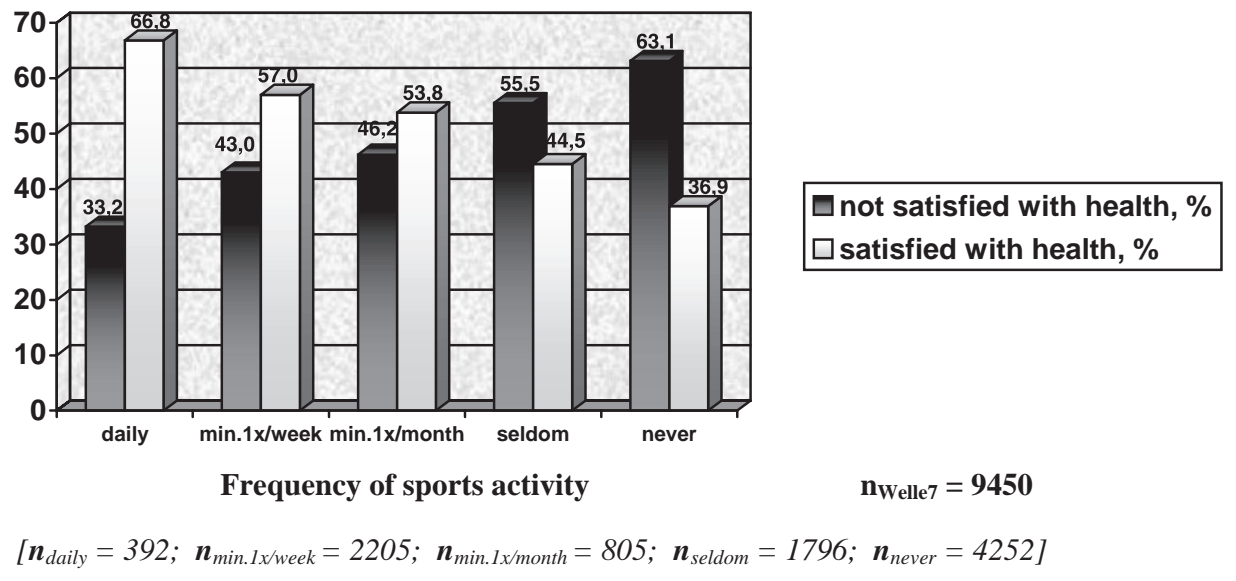

Figure 4. Frequency of sports activity versus life satisfaction.
$57.9 \%$ ) or never (49.6\% versus $46.2 \%$ ). The figures for satisfied people performing exercise a minimum of once a week is $4 \%$ higher in the male group. However, the tendency is the same for both sexes: the share of the life-satisfied decreases in those who exercise rarely (11).

Contentment with health decreases from one age group to the next higher one. Among people under 50 years of age $56.4 \%$ are content with their health. In the following age groups this feeling progressively decreases to only $20 \%$ in the age group of 80 and older. On average, health satisfaction rates $24.7 \%$ among the older adults (11).

Fig. 5 shows the influence of sports and exercise on health satisfaction. Comparing this with Fig. 4, one can see that frequent exercise and sports activities show a positive correlation with perceived health satisfaction. Satisfaction with health rates higher among people who are physically active, for all age groups. Persons who are physically active on a daily basis are the most satisfied with their health; only $36.9 \%$ of people who do not exercise at all are satisfied with their health. The percentage of people satisfied with their health increases from $36.9 \%$ up to $66.8 \%$, the more often exercise is performed.

Comparing the data for men and women, the percentage of men satisfied with their health when performing exercise daily, at least once per week, at least once per month or never is $4.8 \%$ higher than the share of the health-satisfied woman (11).

Fig. 6 shows the association between frequency of sports activity and satisfaction with the scale of leisure time. The percentage of those satisfied with the scale of leisure time who perform exercise daily is $51.9 \%$. The percentages of those content with the scale of leisure time decreases in the following groups: $44.1 \%$ of those who perform sports at least once per week; $39.4 \%$ of those who exercise a minimum of once a month; and $36.3 \%$ of those who seldom exercise. Of the people who never exercise, $46.6 \%$ are content with the scale of their leisure time.

The share of people satisfied with the scale of their leisure time decreases the more seldom they exercise: from $51.9 \%$ (daily exercising) to $36.3 \%$ (seldom exercising). However, the percentage satisfied with the scale of leisure time if they never perform exercise is much higher than in the seldom exercising group, at $46.6 \%$.

Comparing women and men, the percentage of people exercising daily who are satisfied with the scale of their leisure time is much higher for men: $55.3 \%$ as compared with only $45.7 \%$ for women. Thus, men exercising less than daily are only a little more satisfied than the women in the same groups 


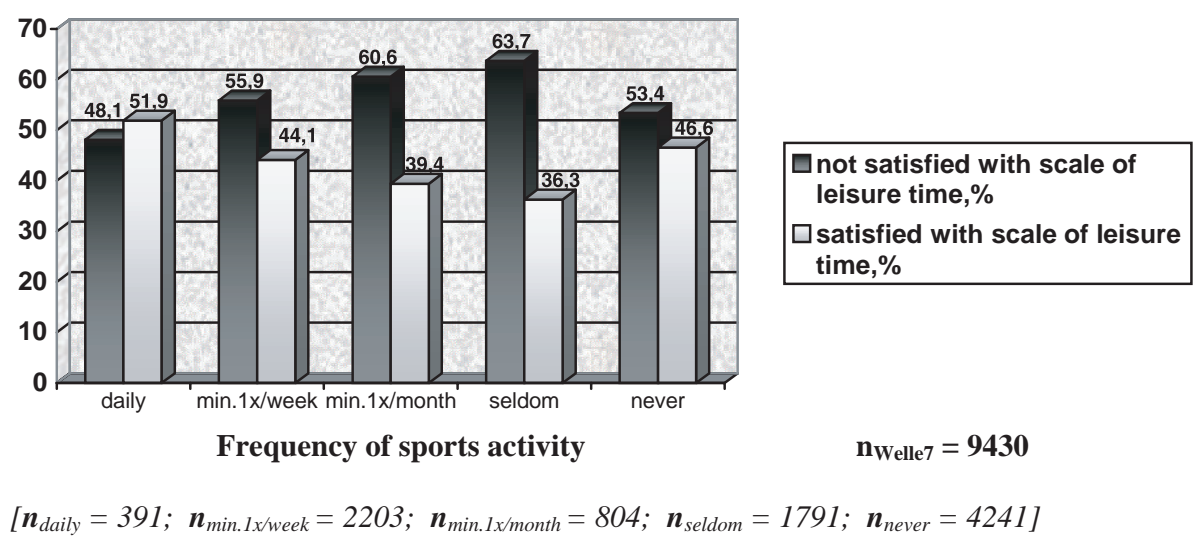

Figure 6. Frequency of sports activity versus satisfaction with the scale of leisure time.

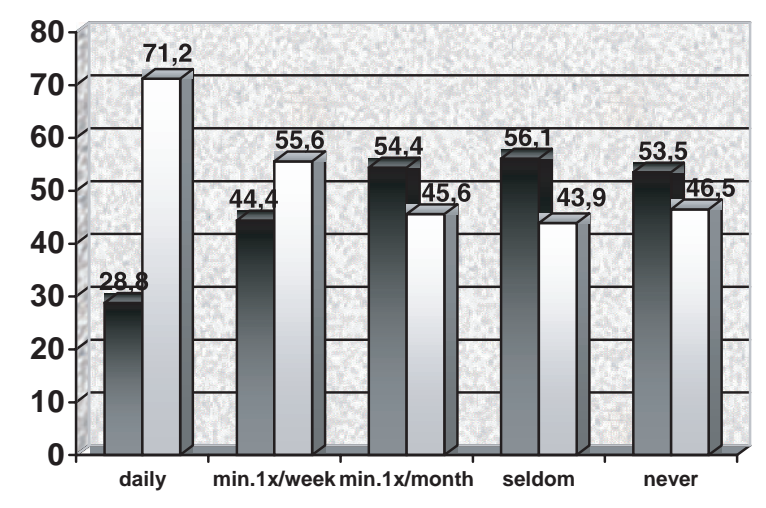

Frequency of sports activity

\author{
$\square$ not satisfied with use of \\ leisure time,\% \\ $\square$ satisfied with use of \\ leisure time,\%
}

Figure 7. Frequency of sports activity versus satisfaction with use of leisure time. (about 2\%); the never exercising men and women are on the same level.

Of the questioned people, those performing daily exercise are $71.2 \%$ satisfied with the use of their leisure time. There is a decrease in the corresponding percentage figures for the other exercise groups: $55.6 \%$ for those exercising at least once a week, $45.5 \%$ for those exercising at least once a month and $43.9 \%$ for those seldom exercising. Of those who never exercise, $46.5 \%$ are satisfied with the use of their leisure time.

A difference between men and women is found in the groups of the people exercising at least once a month or seldom. The share of those satisfied with the use of leisure time is higher in men, $7.3 \%$ (48.6\% versus $41.3 \%)$ and $4.3 \%$ (45.9\% versus $41.6 \%$ ), respectively, than in women (Fig. 7).

\section{Cultural and Artistic Engagement}

Fig. 8 shows the changes of satisfaction with health, depending on the frequency of cultural or artistic engagement during leisure time.

Results show that people who are more active in artistic and cultural pursuits are more satisfied with their health $(57.6 \%$ for daily activities); $53.4 \%$ are content when their engagement is only once a week. Satisfaction with health decreases for those who seldom or never engage in artistic and cultural activities (42.2\%). These figures represent a difference between culturally engaged and non-engaged people of $15.4 \%$.

\section{Grandchildren as a Significant Variable in the Life Satisfaction of Older Adults}

Figs 9 and 10 show the relationship between life satisfaction and the existence of grandchildren in different age groups. Fig. 9 reflects life satisfaction in the different age groups for people with grandchildren, Fig. 10 for those without grandchildren.

Regarding the existence of grandchildren, the study shows that in the 50-59 age group, the percentage of life contentment for those without grandchildren is $9.7 \%$ better, in general, than for those who already have grandchildren. However, in the 70-79 age group, the situation is reversed. Thus, when people get older, life satisfaction increases if there are grandchildren.

Figs 11 and 12 demonstrate how the percentage of people satisfied with their life changes in the different age groups according to the closeness of their relationship to grandchildren. Fig. 11 reflects life satisfaction of those who do not have 


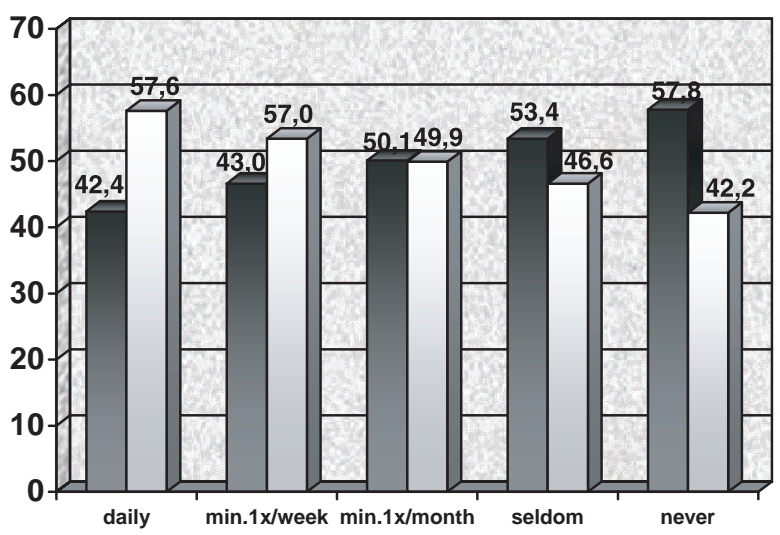

Frequency of artistic and cultural activities

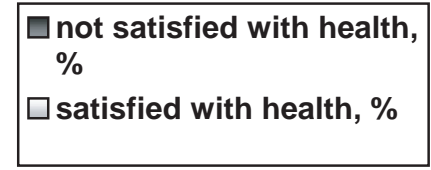

$\mathbf{n}_{\text {Welle7 }}=9446$

$\left[\boldsymbol{n}_{\text {daily }}=255 ; \boldsymbol{n}_{\text {min. } .1 x / \text { week }}=848 ; \boldsymbol{n}_{\text {min. } .1 x / \text { month }}=1053 ; \boldsymbol{n}_{\text {seldom }}=2567 ; \boldsymbol{n}_{\text {never }}=4723\right]$
Figure 8. Frequency of artistic and cultural activities versus health satisfaction.

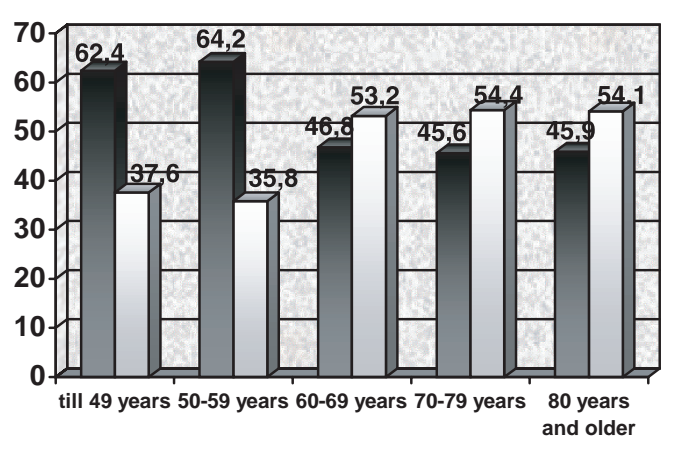

Existence of grandchildren

$\left[\boldsymbol{n}_{\text {till } 49 \text { years }}=348 ; \boldsymbol{n}_{50-59 \text { years }}=876 ; \boldsymbol{n}_{60-69 \text { years }}=718 ; \boldsymbol{n}_{70-79 \text { years }}=362 ; \boldsymbol{n}_{=80 \text { years }}=4243\right]$ 口not satisfied with life in \% $\square$ satisfied with life in \%

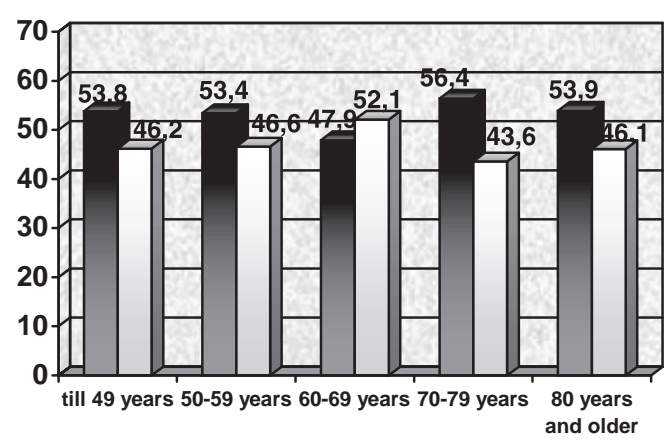

No grandchildren

\section{not satisfied with life in \%}

$\square$ satisfied with life in \%
Figure 9. Age versus life satisfaction of those who have grandchildren. close relationships with grandchildren, whereas Fig. 12 documents the level of life satisfaction of those in different age groups who enjoy close relationships with their grandchildren.

It can be concluded that close relationships with grandchildren significantly influence life satisfaction. In all age groups, the percentage of those content with their life increases, the closer their relationships with their grandchildren. Also remarkable is the finding that life satisfaction increases from the 50-year-old grandparents $(9.2 \%)$ to those aged $60(9.4 \%)$ and those aged $80(19.6 \%)$, if they have close relationships with their grandchildren, compared to those without grandchildren. Life satisfaction is higher for older grandparents. 


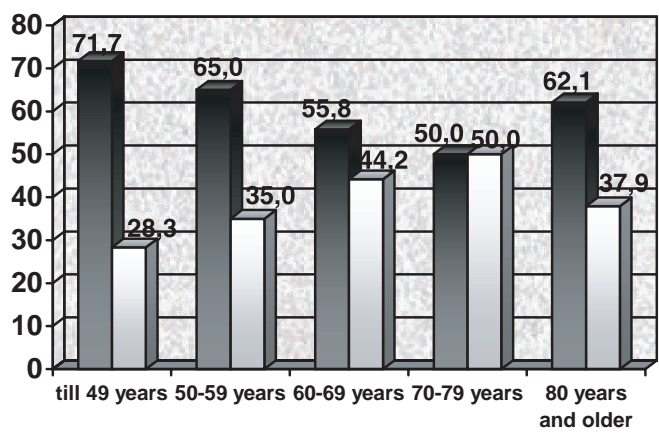

Relationship to the grandchildren not so close

$\left[\boldsymbol{n}_{\text {till } 49 \text { years }}=53 ; \boldsymbol{n}_{50-59 \text { years }}=100 ; \boldsymbol{n}_{60-69 \text { years }}=52 ; \boldsymbol{n}_{70-79 \text { years }}=54 ; \boldsymbol{n}_{=80 \text { years }}=29\right]$

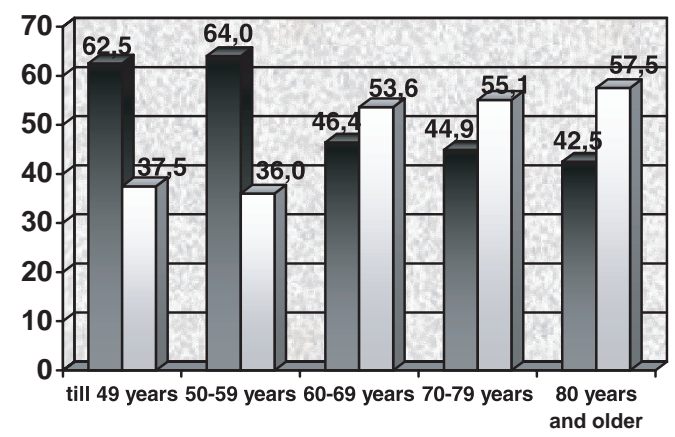

Relationship to the grandchildren close or very close

$\mathbf{n}_{\text {all }}=\mathbf{2 1 0 0}$

$\left[\boldsymbol{n}_{\text {till } 49 \text { years }}=280 ; \boldsymbol{n}_{50-59 \text { years }}=764 ; \boldsymbol{n}_{60-69 \text { years }}=649 ; \boldsymbol{n}_{70-79 \text { years }}=294 ; \boldsymbol{n}_{=80 \text { years }}=113\right]$ 口not satisfied with life in \%

$\square$ satisfied with life in \%
Figure 11. Age versus life satisfaction of those who do not have a close relationship with their grandchildren.

\section{Summary and Discussion}

In order to determine the influence of bodily and mental exercise on fitness and wellness in the older adult population, polls were taken in 1990 and 1991 with about 9400 and 13600 people, respectively. These 'socio-economic' panel polls were analyzed with respect to contentment with life, health and leisure time.

Men and women were equally satisfied with life; percentage figures increased for both at age 60 and higher. In a time of unemployment in Europe, it is important to note that contentment with life is positively linked to contentment with labor. Being employed or having a good job seems to be a stabilizing health factor.

Satisfaction with leisure time activities is closely connected to general life satisfaction. Contentment with life improves the more people engage in artistic and cultural activities, which is also true for those engaged in handicrafts or house-repair (11).

There is a significant positive link between contentment with life and health. Women, however, are, in general, less satisfied with their health than men. As our special interest is focused on exercise activity, it was interesting to note the percentage of $47.7 \%$ non-active persons. It was also astonishing that at the time of the investigation (1990/1991) only $4.1 \%$ performed daily exercise, this percentage being even smaller in the over-50 population $(2.2-2.7 \%)$. The percentage of non-active persons also rises linearly in the over-50 population, which is probably due to orthopedic or other health problems. However, a general limitation on exercise with respect to aging does not exist. On the contrary, in recent years we have found an increase in preventative exercise for older persons in order to prevent heart disease, metabolic syndrome, diabetes, high blood pressure, osteoporosis and cancer. Accordingly, the share of exercise-performing persons over 59 years was raised in our study up to $21.0 \%$.

Nearly half of the people interviewed never engaged in exercise or sport activities. The percentage of those exercising daily was nearly the same in every age category, whereas the percentage of those exercising only occasionally (once a week, once a month or seldom) declines with increasing age. Men engage in exercise more often than women. The more often people exercise, the more satisfied they are with their life, regardless of age. Regular exercise obviously leads to increased fitness which apparently has a positive influence on the immune system and, therefore, is greatly related to enjoyment of other life activities.

It was to be expected that the percentages of men with respect to exercise training would be higher than the figures for women, and consequently the number of daily active men was 
$64.8 \%$, compared with $57.0 \%$ of women who perform no exercise at all. It can be assumed that professional and family stress contributes to this large latter figure. Otherwise, in certain sport groups, especially those for women (osteoporosis prevention and post breast cancer care groups) are well accepted whereas in the coronary and heart exercise groups the men play a dominant role.

Life satisfaction was very dependent on the frequency of active exercise training. It was lowered from $65.8 \%$ down to $48.1 \%$ the less exercise was performed. This is in agreement with a study by E. Emrich who found that high exercise activity can be seen in a positive correlation with life-contentment. In this connection we can confirm that the share of those who are content with their health rises from $36.9 \%$ up to $66.8 \%$, the more frequently exercise is performed. Therefore, exercise has a positive influence on health satisfaction, if it is fully integrated into one's lifestyle. The number of men content with their health is significantly higher in the exercise groups than in those who never exercise, and is also higher with women in the exercise groups. Generally, the fitness feeling is much better in men doing exercise than in woman who are active. It is remarkable that a medical prescription or advice of a medical doctor (GP) is extremely important for the motivation of various people to join an exercise group, because otherwise there are certain mental inhibitions towards exercising within such groups.

Those content with their health are significantly more satisfied with labor and leisure time than those who are not content with their health.

The more often a leisure activity is undertaken the higher the percentage of those satisfied with health. Among those engaging in handicrafts or house-repair, health satisfaction is also the highest when done at least once a month (11). The data demonstrate the important influence of mental activity on health satisfaction. Thus, mental health can positively influence physical health and vice versa, as is already known from the field of psycho-neuroimmunology.

Furthermore, there is a significant relationship between contentment with health and frequency of exercising. The more often people exercised the more content they were with their health; this influence was higher among males than among females.

Contentment with leisure time is equal for males and females and it increases with aging. Satisfaction with leisure time is positively linked to satisfaction with labor, since leisure seems to be regarded as a 'reward' for hard work. The more often exercise activity was undertaken, the more content people were with their leisure time; this is also true for those engaging in handicrafts (11).

There is a significant relationship between contentment with leisure time and satisfaction with health. Satisfaction with leisure time increases with the frequency of exercise engagement. The share of those who are content with their health of those content with their leisure time is only $10.7 \%$ higher than those who are not content with their leisure time. The health aspect of leisure time seems to be not as significant as expected on the basis of exercise activity. The percentage of men content with their leisure time is about $9.6 \%$ higher than for women (53.3\% versus $45.7 \%)$. The share of those content with the scale of their leisure time decreases by $15.6 \%$ with decreasing exercise activity: from $51.9 \%$ of the daily active persons down to $36.3 \%$ of those who seldom exercise. In the never-exercise group, the percentage of those content with the scale of their leisure time rises from this low point by $10.3 \%$ up to $46.6 \%$ in cases where people enjoy other hobbies and leisure time activities besides sport. With regard to contentment with leisure time, there is a $27.3 \%$ difference between the figures for those who exercise daily $(71.2 \%$ content) and those exercising seldom (43.9\% content). Accordingly, exercise has a high value with respect to a satisfying leisure time. In spite of this fact, those who never exercised were also content with the use of their leisure time. From our data (11) it could be deduced that women are more motivated with respect to exercise than men. This can be especially observed when looking at the activity of female walking groups nowadays. On the other hand, women are not satisfied when they are inhibited by other work from performing exercise.

An important aspect for aging nowadays is that people need to keep fit in order to avoid premature nursing. The ability to take care of oneself becomes a critical aspect for one's social, medical and financial well being. Thus, strategies for good health and general fitness need to be developed and realized. An interesting by-product of this study was the contentment with life in relation to the existence of grandchildren and the closeness to them.

People not satisfied with their health more frequently had more children. Life satisfaction is higher only for grandparents at age 60 and up, whether the connection to the grandchildren is close or not. Health-contentment of those with grandchildren is higher only in persons aged 80 years and above. The feeling of biological survival apparently influences life satisfaction.

The percentage of those satisfied with leisure time is higher for those with children than for childless individuals. This percentage decreases with an increase in hours spent daily in childcare (11). Grandparents are more content with leisure time than people without grandchildren. The closer the relationship to grandchildren (parents who are employed or grandparents living in the near neighborhood or in the same house), the more content are the grandparents with their leisure time. Older people are quite eager to fulfill the new roles associated with grandchildren, which includes more physical and mental activities. Obviously, having meaningful tasks to undertake make people of 60 and older more content then those having meaningless perspectives.

So far, our findings imply that a meaningful task, an optimistic outlook on life, a promising perspective, a perceived successful life as well as the wish to remain healthy and fit positively influence life satisfaction.

Summarizing the results of the study, the following suggestions can be postulated in order to ensure physical 
and psychological well-being, not only in older adults but also as complementary strategies for ill people and those in rehabilitation programs, as well as in psychological coping techniques with patients:

(i) Regular, daily if possible, exercise routines should be performed in order to ensure general well-being and the ability to look after oneself (see also 13-15).

(ii) On the basis of several investigations it is suggested that exercise sufficient to burn 2000-2500 kcal per week [ $(1 \mathrm{~min}$ jogging $=\sim 10 \mathrm{kcal}$; other tables can give concrete information, also with respect to the body mass index (BMI)] should be performed three to four times a week. In addition, life-style change should also include reduction of the BMI and a change in nutritional behavior.

(iii) Daily mental training (not by passive TV watching), e.g. participation in cultural events or personal hobbies such as arts and crafts, should be engaged in, because the immune system has its origin in the brain and accordingly can be influenced by the central nervous system.

(iv) A good relationship with children and grandchildren should be established ('grand family feeling') in order to ensure the feeling of having necessary tasks, the safety of a nest and the enjoying of the 'sunset feeling' of a successful life. In addition, the vision of a biological immortality may strengthen health.

It is assumed that these suggestions stabilize the psychoneuroimmunological network, slow down the physical and mental aging processes, prevent premature disabilities and may be very useful in treating patients during, and especially after, severe illnesses, the results of which are reported by Beuth (1). As the costs of clinical and geriatric care are becoming more expensive, regular exercise, mental fitness and psycho-social interests are of increasing importance for coping not only with the 'stress' of belonging to the 'old, but useless people', but also with respect to a promising and successful rehabilitation strategy as is already known from heart sport groups and those sport groups dealing with cancer survivors: the number of the latter in Germany amounts to $\sim 350$.

\section{Acknowledgments}

The project was sponsored by Deutsche Forschungsgemeinschaft and supervised by Infratest, Munich. The data were kindly given to us by Prof. Dr Gert Wagner, German Institute for Economical Research, Berlin. We are greatly indebted to him for this generous help and for his friendly advice.

\section{References}

1. Beuth J. Krebs ganzheitlich behandeln. Stuttgart: Trias Therapie Kompass, 2003.

2. Uhlenbruck G. Sport, Alter und Immunsystem. Med Welt 1993;44:303-8

3. Schnohr P, Scharling H, Jensen JS. Changes in Leisure-time Physical Activity and Risk of Death: An Observational Study of 7000 Men and Women. Am J Epidemiol 2003;158:639-44.

4. Beuth J. Grundlagen der Komplementäronkologie. Stuttgart: Hippokrates, 2002

5. Abele A, Becker P (Herausgeber). Wohlbefinden: Theorie, Empirie, Diagnostik. Weinheim, München: Juventa-Verlag, 1991.

6. McConatha J, McConatha $\mathrm{D}$. The study of the relationship between wellness and life satisfaction of older adults. Activities Adaptation Aging 1989;13:129-140.

7. Diener E. Subjective wellbeing. Psycholog Bull 1984;95:542-5.

8. Lin E. Social support, stressful life-events, and illness: A model and an empirical test. J Health Soc Behav 1979;20:108-19.

9. Havighurst R. Social roles, work leisure, and evaluation. In: Eisdörfer C, Lawton M, editors, The Psychology of Adult Development and Aging. Washington, DC: American Psychological Association, 1973.

10. Aaron DJ, Kriska AM, Dearwater SR, Cauley JA, Metz KF, LaPorte RE. Reproducibility and Validity of an Epidemiologic Questionnaire to Assess Past Year Physical Activity in Adolescents. Am J Epidemiol 1995; 142:191-201

11. Mielke C. Wohlbefinden und Fitness: Eine empirische Analyse zur Lebens-, Gesundheits- und Freizeitzufriedenheit älterer Menschen. Dissertation, Medical Faculty, University of Cologne, Germany, 1997.

12. Deutsches Institut für Wirtschaftsforschung (Herausgeber). Das Sozioökonomische Panel (SOEP), Benutzerhandbuch Version 7. Berlin, November 1993.

13. Booth FW, Tseng BS. America needs to exercise for health. Med Sci Sports Exerc 1995;462-465.

14. Macera CA, Croft JB, Brown DR, Ferguson JE, Lane MJ. Predictors of Adopting Leisure-Time Physical Activity among a Biracial Community Cohort. Am J Epidemiol 1995;142:1-7.

15. Paffenbarger RS, Hyde RT, Wing AL, Lee I-M, Jung DL, Kampert JB. The association of changes in physical-activity level and other lifestyle characteristics with mortality among men. N Engl J Med 1993;328: 538-45.

16. Uhlenbruck G. Wie Sporttreiben psychische Funktionen beeinflusst. $T W$ Sport Medizin 1993;5-6:395-8.

Received January 6, 2004; accepted March 24, 2004 


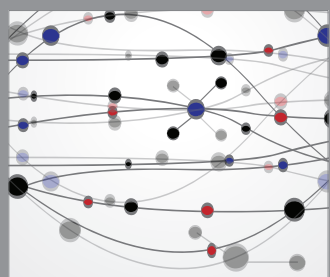

The Scientific World Journal
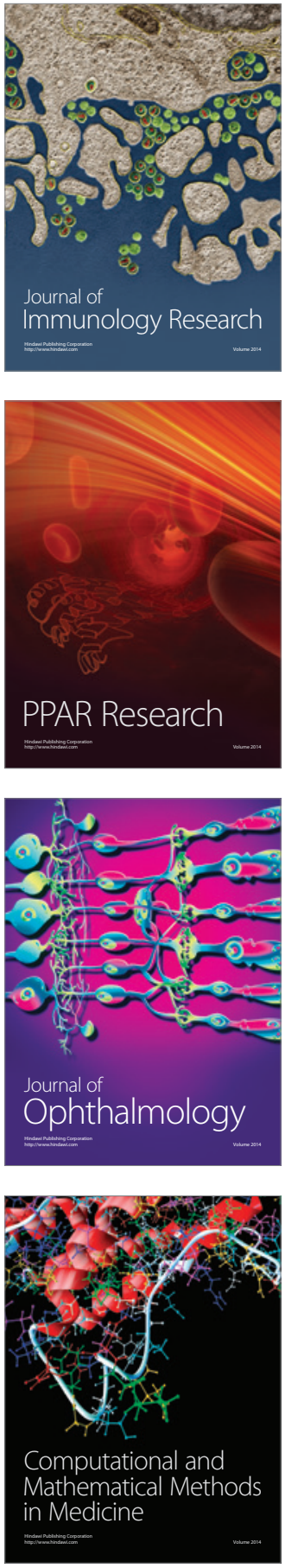

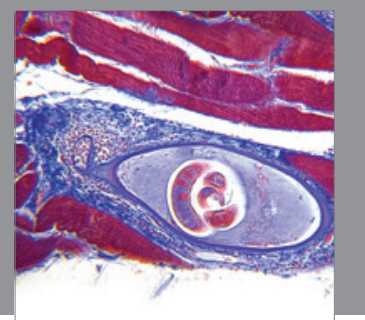

Gastroenterology

Research and Practice
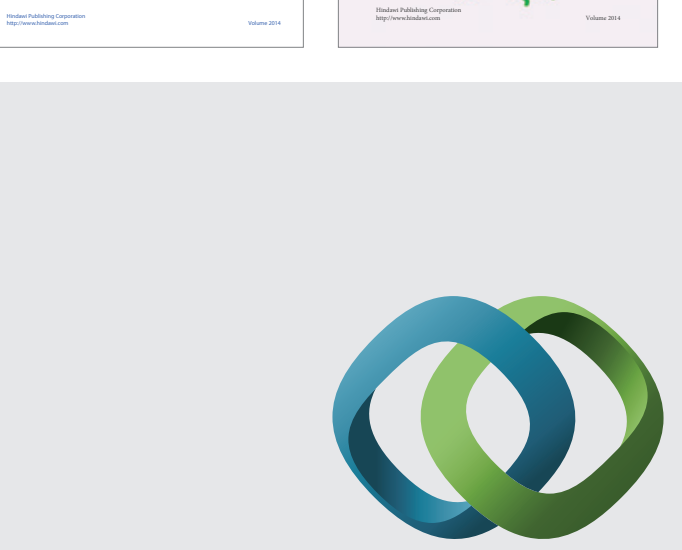

\section{Hindawi}

Submit your manuscripts at

http://www.hindawi.com
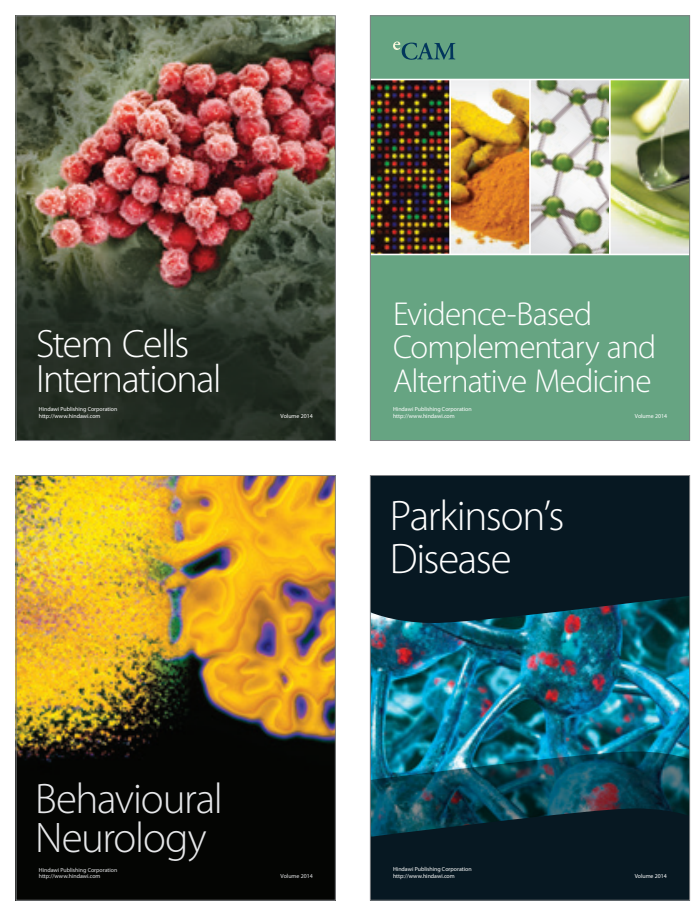

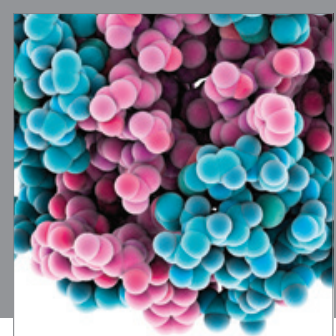

Journal of
Diabetes Research

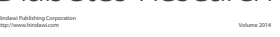

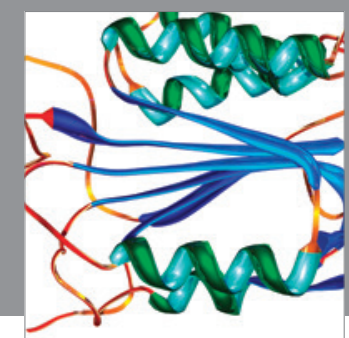

Disease Markers
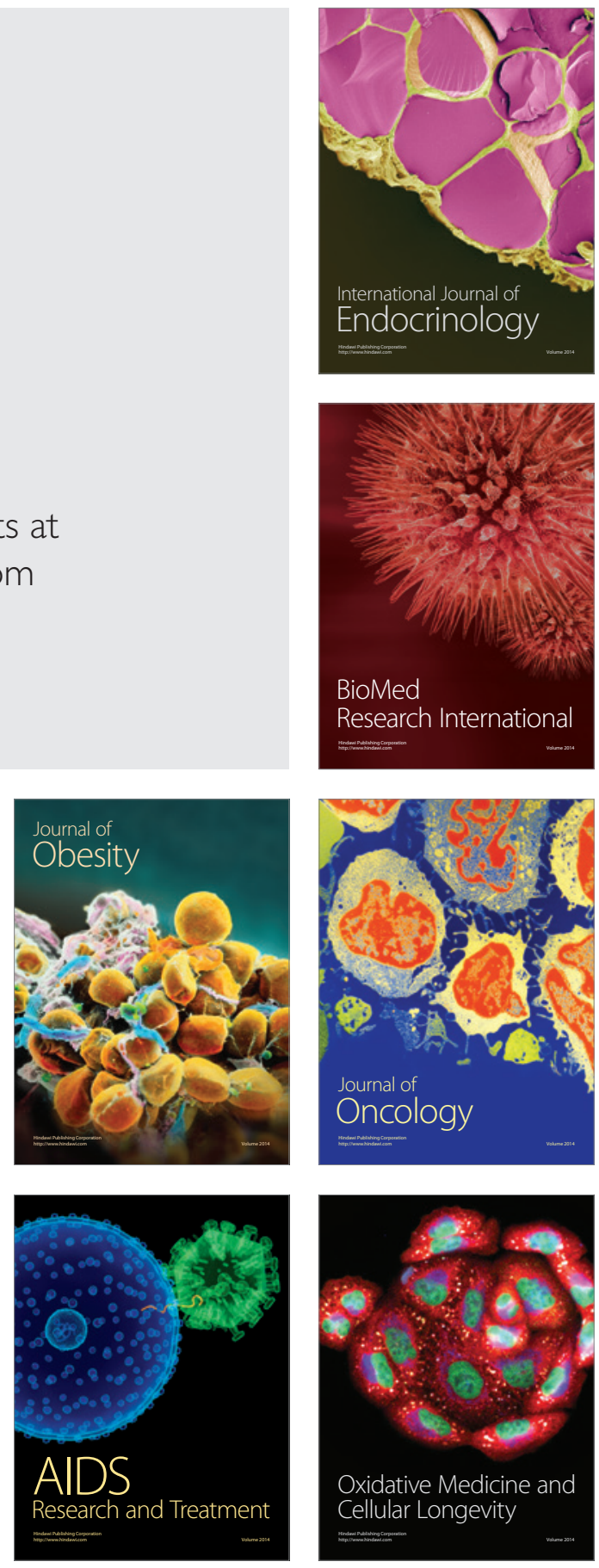